\title{
Heterozygous Thr 135 Ala polymorphism at leucine-rich repeat (LRR) in genomic DNA of toll-like receptor 4 in patients with poorly-differentiated gastric adenocarcinomas
}

\author{
TADASHI OHARA ${ }^{1}$, TETSUO MORISHITA ${ }^{1}$, HIDEKAZU SUZUKI $^{2}$ and TOSHIFUMI HIBI ${ }^{2}$ \\ ${ }^{1}$ Department of Internal Medicine, Tokyo Dental College, Chiba 261-8502; \\ ${ }^{2}$ Department of Internal Medicine, Keio University, School of Medicine, Tokyo 160-8582, Japan
}

Received January 16, 2006; Accepted March 1, 2006

\begin{abstract}
The genomic DNA of toll-like receptor (TLR) 2, TLR4, radioprotective 105, TLR6, and TLR9 were examined for mutations in 48 patients with gastric cancer. Of these, 22 had well-differentiated and 20 had poorly-differentiated adenocarcinomas, the latter group including 10 with signet ring cell carcinomas. The remaining 6 had gastric adenomas. Ten healthy volunteers with no family history of malignant diseases served as controls. DNA was extracted from peripheral blood and subjected to electrophoresis using PCR oligonucleotide primers. The resultant gel was analyzed with a DNA sequencer. None of the healthy volunteers, patients with gastric adenomas or those with well-differentiated gastric adenocarcinomas showed mutations. However, 8 of the 20 with poorly-differentiated gastric adenocarcinoma showed heterozygosity at the 135th position of the amino acid sequence of TLR4, and a mutation from threonine to alanine was found at this site. Analysis of the entire available amino acid sequence of TLR4 revealed that this mutation occurred at a leucine-rich repeat corresponding to one of its extracellular components. This suggests a disturbance in the protein phosphorylation reaction of TLR4, and that this disturbance is related to the development of poorly-differentiated gastric adenocarcinomas.
\end{abstract}

\section{Introduction}

Toll-like receptors (TLRs) were first recognized as molecules involved in innate immunity and their physiological function was later clarified. Recent studies have revealed that they also serve as the starting point in the inflammation and immune reaction systems in both innate and acquired immunity where

Correspondence to: Dr Tadashi Ohara, Department of Internal Medicine, Tokyo Dental College, 1-2-2 Masago, Mihama-ku, Chiba 261-8502, Japan

E-mail: tohara@tdc.ac.jp

Key words: leucine-rich repeat, toll-like receptor, gastric adenocarcinoma they variously act as the medium of reactions $(1,2)$. TLRs are type I membrane proteins and one of their extracellular components includes a structure known as a leucine-rich repeat (LRR), which is involved in protein-binding. It has been reported that LRRs are composed of 20 to 29 leucine amino acid residues (Leu) (3). Their intracellular components are associated with the Toll/IL-1R domain, which resembles an interleukin-1 receptor (IL-1R). By means of the LRR structure, TLRs recognize each corresponding pathogenassociated molecular pattern (PAMP). Ten types of TLR (TLR1-10) have been recognized in humans (4). Signaling via the expression of these TLRs controls the physiopathology of various diseases; it has also been proven that polymorphisms of TLRs are involved in physiopathological control (5-7). There have been no reports, however, on the relationship between gastric cancer and such polymorphisms. In this study, we examined TLR2 and TLR4, radioprotective 105 (RP105, a member of the TLR4 family), TLR6 and TLR9 for possible mutations in their genomic DNA in patients with gastric cancer.

\section{Patients and methods}

The subjects consisted of 48 patients with gastric cancer (mean age, 66.7 years). Twenty-two of these had well-differentiated adenocarcinomas [H.pylori (Hp)-positive, 17; Hp-negative, 5], 20 had poorly-differentiated adenocarcinomas (including 10 with signet ring cell carcinomas, Hp-positive, 9; Hp-negative, 11 ), and 6 had gastric adenomas [mean age, 62.1 years, moderate atypia, 4 (Hp-positive, 3; Hp-negative, 1); severe atypia, 2 (Hp-positive, 2; Hp-negative, 0)]. Ten healthy volunteers (mean age, 63.8 years) with no family history of malignant diseases (Hp-positive, 8; Hp-negative, 2) served as controls. Peripheral blood was collected from all patients and controls and used to extract DNA. Following electrophoresis by PCR using the PCR oligonucleotide primers for TLR2, TLR4, RP105, TLR6 and TLR9, the gels were analyzed for DNA sequences with a DNA sequencer, to determine the possible presence of mutations. Informed consent was obtained from all of the patients and volunteers prior to the study.

DNA isolation. A Genomix kit (TALET, Italy) was used to extract the DNA from the peripheral blood cells. After addition of a buffy coat, the specimens were heated for $15 \mathrm{~min}$ at $65^{\circ} \mathrm{C}$. 
A

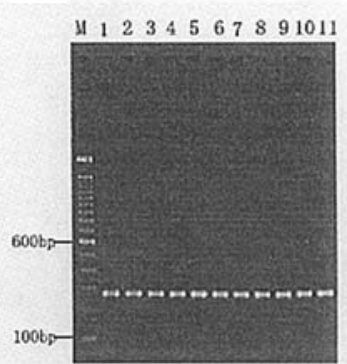

TLR2

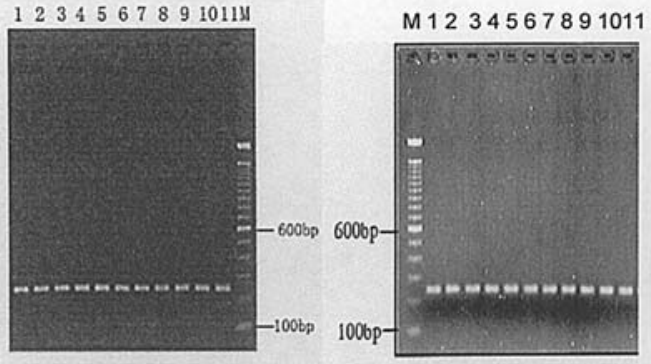

TLR4

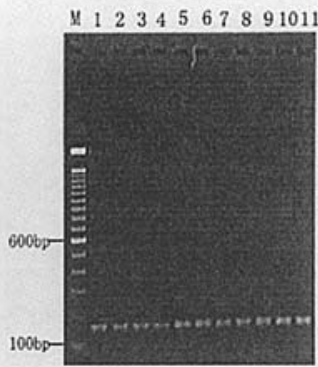

TLR6

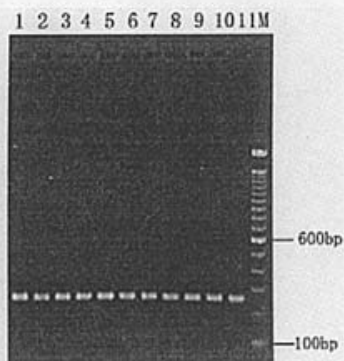

TLR9

M. Molecular marker

1. Gastric cancer (well), H.pylori (-)

2. Gastric cancer (sig), H.pylori $(+)$

3. Gastric cancer (well), H.pylori $(+)$

4. Gastric adenoma (moderate atypia), H.pylori (-)

5. Gastric cancer (well), H.pylori (-)

6. Gastric adenoma (severe atypia), H.pylori $(+)$

7. Gastric cancer (por), H.pylori (-)

8. Gastric cancer (well), H.pylori $(+)$

9. Gastric cancer (por), H.pylori $(+)$

10. Gastric cancer (por), H.pylori $(+)$

11. Gastric cancer (sig), H.pylori (-)

\section{B}

TRL2

TLR4
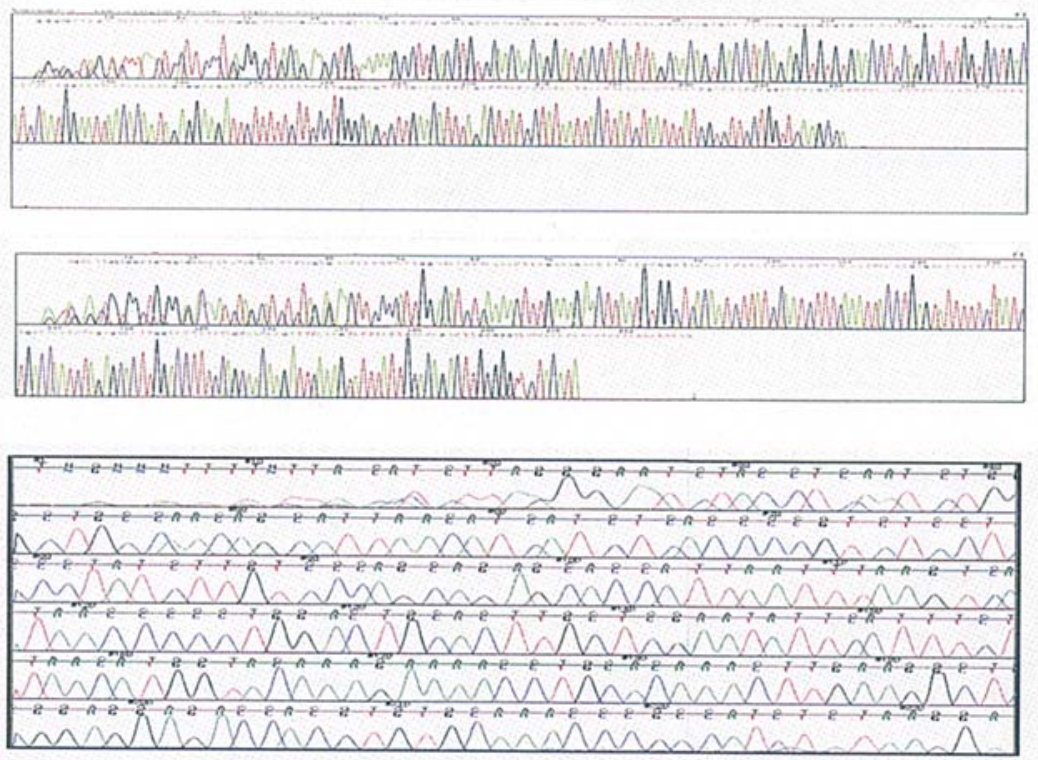

TLR6

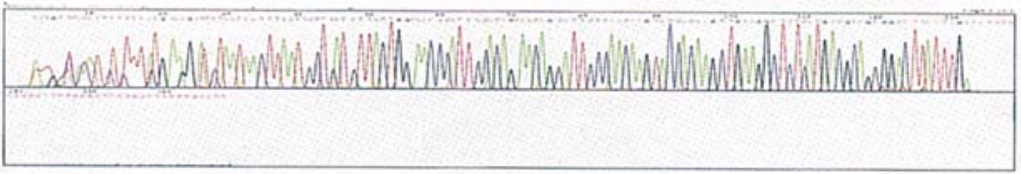

TLR9

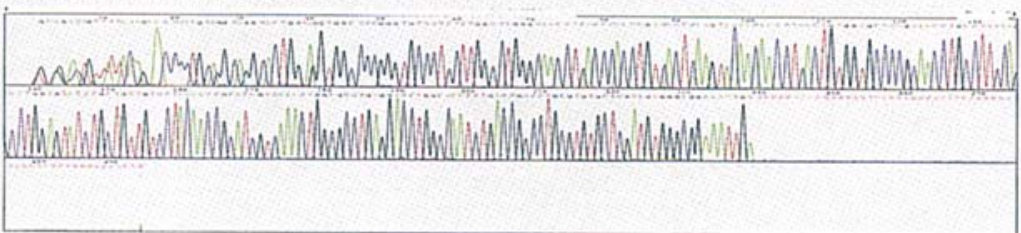

Figure 1. (A) Expression of TLRs and RP105 analyzed by Gene Amp PCR System 9700. Well, well-differentiated adenocarcinomas; por, poorly-differentiated adenocarcinomas; sig, signet ring cell carcinomas. (B) Chromatograph of TLRs and RP105 DNA sequence without mutations. 
Table I. Results of examination of mutations in TLRs and RP105.

\begin{tabular}{|c|c|c|c|c|c|c|}
\hline & $\begin{array}{l}\text { H.pylori } \\
\text { infection }\end{array}$ & TLR2 & TLR4 & RP105 & TLR6 & TLR9 \\
\hline Well-differentiated & + & $0 / 17$ & $0 / 17$ & $0 / 17$ & $0 / 17$ & $0 / 17$ \\
\hline adenocarcinomas $(n=22)$ & - & $0 / 5$ & $0 / 5$ & $0 / 5$ & $0 / 5$ & $0 / 5$ \\
\hline \multicolumn{7}{|l|}{$\begin{array}{l}\text { Poorly-differentiated } \\
\text { adenocarcinomas }(n=20)\end{array}$} \\
\hline \multirow[t]{2}{*}{ por } & + & $0 / 5$ & $2 / 5^{\mathrm{a}}$ & $0 / 5$ & $0 / 5$ & $0 / 5$ \\
\hline & - & $0 / 5$ & $2 / 5^{\mathrm{a}}$ & $0 / 5$ & $0 / 5$ & $0 / 5$ \\
\hline \multirow[t]{2}{*}{ sig } & + & $0 / 4$ & $1 / 4^{\mathrm{a}}$ & $0 / 4$ & $0 / 4$ & $0 / 4$ \\
\hline & - & $0 / 6$ & $3 / 6^{\mathrm{a}}$ & $0 / 6$ & $0 / 6$ & $0 / 6$ \\
\hline \multicolumn{7}{|l|}{ Gastric adenomas $(n=6)$} \\
\hline \multirow[t]{2}{*}{ Moderate atypia } & + & $0 / 3$ & $0 / 3$ & $0 / 3$ & $0 / 3$ & $0 / 3$ \\
\hline & - & $0 / 1$ & $0 / 1$ & $0 / 1$ & $0 / 1$ & $0 / 1$ \\
\hline \multirow[t]{2}{*}{ Severe atypia } & + & $0 / 2$ & $0 / 2$ & $0 / 2$ & $0 / 2$ & $0 / 2$ \\
\hline & - & $0 / 0$ & $0 / 0$ & $0 / 0$ & $0 / 0$ & $0 / 0$ \\
\hline \multirow[t]{2}{*}{ Healthy volunteers $(n=10)$} & + & $0 / 8$ & $0 / 8$ & $0 / 8$ & $0 / 8$ & $0 / 8$ \\
\hline & - & $0 / 2$ & $0 / 2$ & $0 / 2$ & $0 / 2$ & $0 / 2$ \\
\hline
\end{tabular}

Denominator of fraction indicates case numbers and numerator indicates number of genomic DNA mutations. ${ }^{\mathrm{a} H e t e r o z y g o s i t y . ~ P o r, ~ p o o r l y-~}$ differentiated adenocarcinomas; sig, signet ring cell carcinomas.

Then, $3 \mathrm{ml}$ of chloroform was added, followed by further mixing for $5 \mathrm{~min}$. The specimens were then centrifuged at $3000 \mathrm{rpm}$ for $10 \mathrm{~min}$. The upper layers were collected and centrifuged again at $3000 \mathrm{rpm}$ for $10 \mathrm{~min}$. The supernatants were decanted, and the precipitates were completely dissolved using a vortex mixer. One hundred percent Ethanol $(3 \mathrm{ml})$ was then added to precipitate the DNA. The obtained DNA was dissolved in TE buffer and DNA concentrations were determined by spectrophotometry.

PCR method. 10X PCR buffer (200 mM Tris- $\mathrm{HCl} \mathrm{pH} 8.4$, $500 \mathrm{mM} \mathrm{KCl}$ ) was added to $50 \mathrm{mM} \mathrm{MgCl}_{2}$ to achieve a concentration of $1 \mathrm{mM} ; 10 \mathrm{mM}$ dNTPs were then added to a concentration of $200 \mu \mathrm{M}$; finally, $50 \mu \mathrm{M}$ each of forward and reverse primers were added to obtain a concentration of $0.5 \mu \mathrm{M}$. Plasmid DNA was added as the template, for the amplification reaction to achieve $\sim 0.01 \mathrm{fM}$, after which, 2.5 units of KOD-plus-DNA polymerase (Toyobo) were added. A Gene Amp PCR System 2400 (Perking-Elmer) was used for PCR amplification. The PCR product was subjected to $0.8 \%$ agarose gel electrophoresis, and amplification of DNA fragments to the target length was confirmed. The following PCR oligonucleotide primers were used for the present study: TLR2, forward, tatgacgcaatggtatctg; reverse, ggcttgaacca ggaagacga; TLR4, forward, ggagcettttctggactatc; reverse, atgtagaacccgcaagtctg; RP105, forward, aacagcetgacatg cgacag; reverse, ccttagagatggcgggttg; TLR6, forward, gtggtg ccattaccgaactct; reverse, caaataaagtccactgcgtca; TLR9, forward, tgcctgcgettcctattca; reverse, caatttccgcccacatcgag.
Base sequence determination. The base sequence was determined by means of the chain elongation reaction termination method using dideoxynucleotide. The ABI PRISM and a BigDye $^{\mathrm{TM}}$ terminator cycle sequencing ready reaction kit (Applied Biosystems) were used with plasmid DNA (0.2 to $0.5 \mu \mathrm{g})$ as the template. For this reaction, a reaction mixture with a total volume of $20 \mu \mathrm{l}$, consisting of $8.0 \mu \mathrm{l}$ of terminator ready reaction mix, $0.2-0.5 \mu \mathrm{g}$ of template, $3.2 \mathrm{pmol}$ of primer, and ddH2O q.s., was prepared using the Gene Amp PCR System 2400 (Perking-Elmer). The reaction conditions were as follows: 25 cycles at $96^{\circ} \mathrm{C}$ for $10 \mathrm{sec}$, at $50^{\circ} \mathrm{C}$ for $5 \mathrm{sec}$, and at $60^{\circ} \mathrm{C}$ for $4 \mathrm{~min}$. Subsequently, the system was incubated at $4^{\circ} \mathrm{C}$. After completion of the reaction, the reaction liquid was pre-cipitated with ethanol. After elimination of the supernatant, the system was washed with $70 \%$ ethanol and dried under reduced pressure. The precipitate was dissolved in $50 \mu 1$ of TSR, degenerated for $2 \mathrm{~min}$ at $95^{\circ} \mathrm{C}$, and allowed to stand on ice. The resultant DNA sequence was analyzed using an Applied Biosystems 3730 DNA analyzer.

\section{Results}

TLR2, TLR4, RP-105, TLR6 and TLR9 were expressed uniformly in all samples by PCR gel electrophoresis (Fig. 1A). Fig. 1B shows the chromatograph of DNA sequences for TLR2, TLR4, RP105, TLR6 and TLR9 obtained by PCR gel electrophoresis where no mutations were present.

No mutations were noted in the genomic DNAs of TLR2, TLR4, RP105, TLR6, or TLR9 that were collected from 


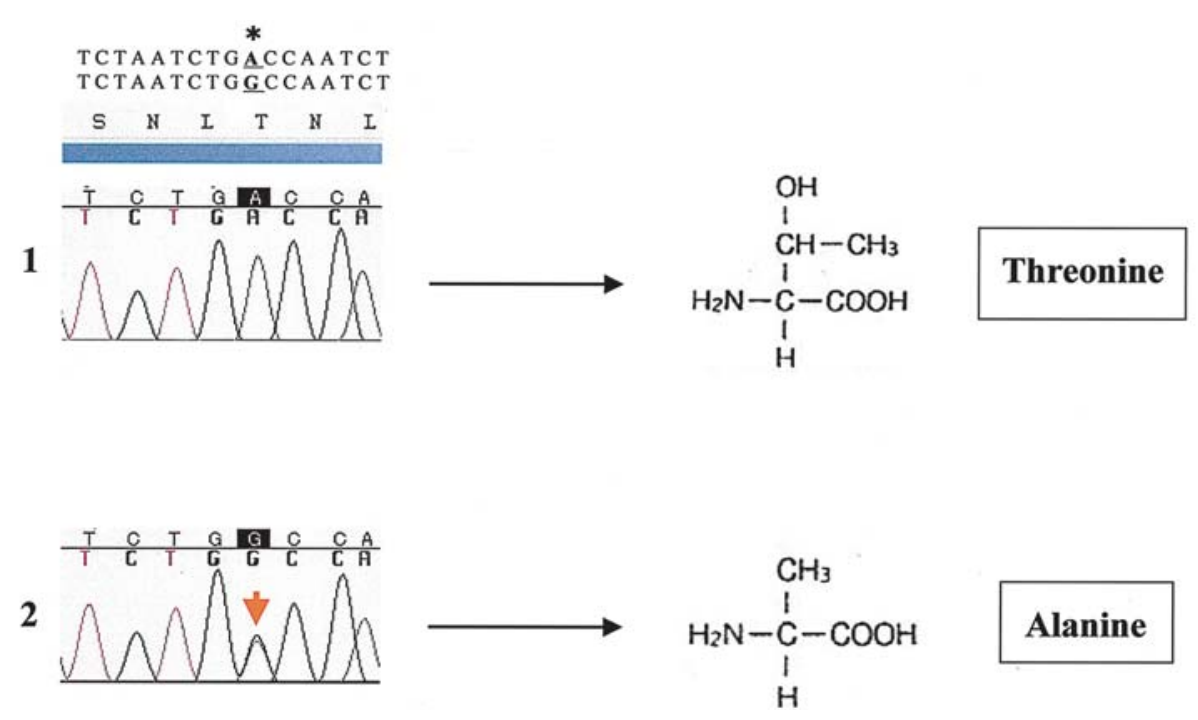

Figure 2. Results of the chromatograph of TLR4 DNA sequence and changes of the structure of amino acid with and without mutations. Case 1 shows a case without mutations; Case 2 shows a case with heterozygosity. Red arrow indicates heterozygous point. "135th position in amino acid sequence of TLR4.

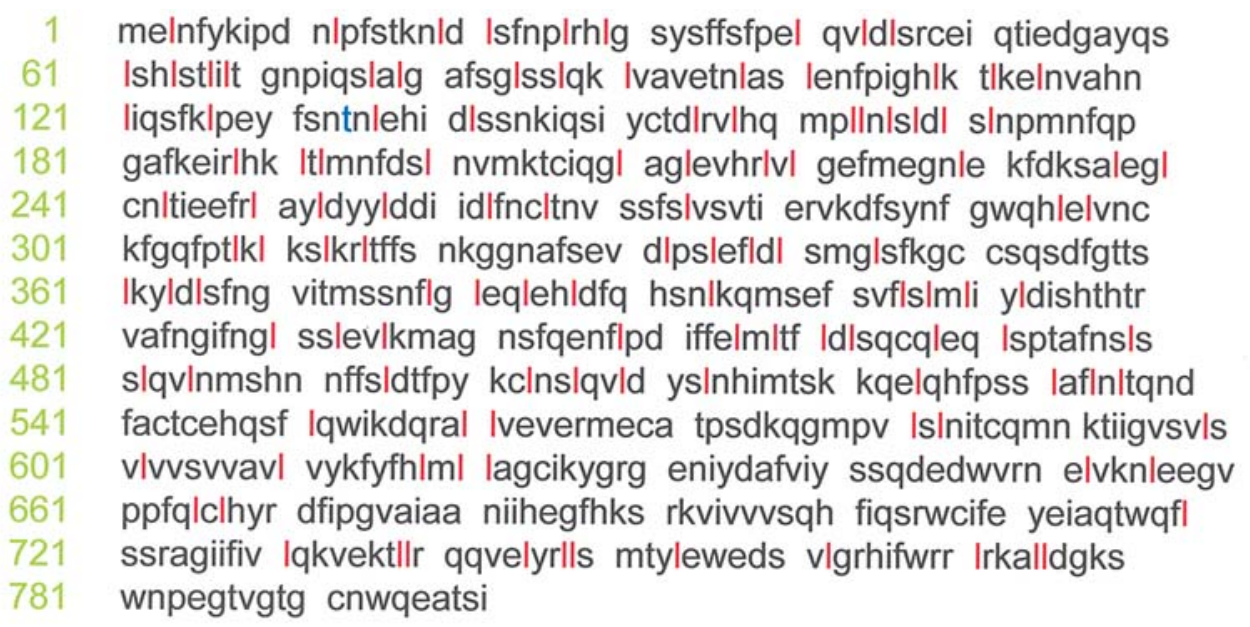

Figure 3. Entire amino acid sequence of TLR4 in humans. Red font ' 1 ' indicates leucine and blue font ' $t$ ' at 135 th position of amino acid sequence indicates threonine.

the normal controls or patients with gastric adenomas or well-differentiated gastric adenocarcinomas. For 8 of the 20 with poorly-differentiated gastric adenocarcinomas, heterozygosity was noted at the 135 th position of the amino acid sequence of TLR4. It was found that this heterozygosity resulted in threonine being replaced by alanine. Among the 8 patients broadly classified as having poorly-differentiated gastric adenocarcinomas, 4 were further sub-classified as having signet ring cell carcinomas. When this change in those patients with poorly-differentiated gastric adenocarcinomas was classified, according to the presence or absence of $\mathrm{Hp}$ infection, no correlation was found between the two (3 out of 9 among the Hp-positive cases and 5 out of 11 among the Hpnegative cases) (Table I and Fig. 2). The entire available amino acid sequence of TLR4 was found to consist of 799 amino acid residues, with leucine occurring 127 times over the entire length of the sequence (leucine content, 15.9\%). The rate of occurrence of leucine was particularly high between 60 and
180, being found 28 times (23\%) at this location; and it was at this site that threonine had been replaced with alanine (Fig. 3).

\section{Discussion}

TLR2, TLR4 and RP105, TLR6, and TLR9 recognize peptidoglycan, lipopolysaccharide (LPS), lipoprotein, and $\mathrm{CpG}$ DNA as PAMPs, respectively. RP105, a member of the TLR 4 family, forms a complex with MD1 (a secretory protein) on B cells to recognize LPS (7). In this study, only TLR4 from the patients with poorly-differentiated gastric adenocarcinomas displayed a mutation in its genomic DNA. The heterozygosity at the 135th position in the amino acid sequence of TLR4 (the mutation of threonine into alanine at this position) occurred regardless of the presence or absence of Hp infection. About 20 types of amino acid have been reported, but only 3 (serine, threonine and tyrosine) contain a hydroxyl group within their structure (alanine does not fall within this 
category). For a protein phosphorylation reaction to take place, an amino acid must contain a hydroxyl group within its structure. This reaction plays an important role in regulating dynamic changes in protein structures and functions, to control protein kinase activities through the stereo-structures of cells and protein interactions, thus enabling intercellular signal transmission. Amino acids containing a hydroxyl group are thus responsible for the regulation of various biological phenomena. The replacement of threonine with alanine at the 135 th position of the amino acid sequence in TLR4 results in dysfunction of protein phosphorylation. Recently, the relationship between protein phosphorylation and the onset of diseases such as cancer, cardiovascular disease, diabetes mellitus and Alzheimer disease has come under scrutiny. TLR4 manifests its physiological action by forming a complex with MD2, a secretory protein (9). What should be noted here is that the TLR4 mutation found in this study occurred at LRR, where the binding of MD2 takes place. The expression of TLRs has been noted not only in epithelial cells (10) but also in macrophages (11), dendritic cells (12), mast cells (13), fibroblasts (14), vascular endothelial cells (13) and even in T cells (15) and B cells (16). Furthermore, the ligands of TLR4 are not limited to viruses and bacteria and it has been proven that fibronectin (17), hyaluronic acid (18), fragments of heparin sulfate (19), HSP60 (20) and HSP70 (21) may also act as ligands. These reports strongly suggest that dysfunction of protein phosphorylation caused by genomic mutation of TLR4 in a host leads to various physiopathologic states. It remains to be determined how a host that has a mutated TLR4 develops a poorly-differentiated gastric adenocarcinoma; however, we believe that the results of this study suggest a significant finding with important implications for clinical medicine.

\section{Acknowledgements}

We declare that there is no conflict of interest. This work was supported by research subsidies from Takeda Pharmaceutical Industry Corporation, Japan. The sponsor of the study had no role in study design, data collection, data analysis, data interpretation, or writing of the report. Dr Tadashi Ohara had full access to all the data in the study and had final responsibility for the decision to submit for publication. We are grateful to Jeremy Williams, Associate Professor of Tokyo Dental College, Laboratory of International Dental Information for his advice on this work.

\section{References}

1. Takeda K and Akira S: Toll-like receptors in innate immunity. Int Immunol 17: 1-14, 2005.
2. Goldstein DR: Toll-like receptors and other links between innate and acquired alloimmunity. Curr Opin Immunol 16: 538-544, 2004.

3. Kobe B and Deisenhofer J: Proteins with leucine-rich repeats. Curr Opin Struct Biol 5: 409-416, 1995.

4. Akira S, Takeda K and Kaisho T: Toll-like receptors: critical proteins linking innate and acquired immunity. Nat Immunol 2: 675-680, 2001 .

5. Berdeli A, Celik HA, Ozyurek R, et al: TLR-2 gene Arg753Gln polymorphism is strongly associated with acute rheumatic fever in children. J Mol Med 83: 535-541, 2005.

6. Schroder NW, Meister D, Wolff V, et al: Chronic periodontal disease is associated with single-nucleotide polymorphisms of the human TLR-4 gene. Genes Immun 6: 448-451, 2005.

7. Schroder NW and Schumann RR: Single nucleotide polymorphisms of Toll-like receptors and susceptibility to infectious disease. Lancet Infect Dis 5: 156-164, 2005.

8. Nagai Y, Shimazu R, Ogata H, et al: Requirement for MD-1 in cell surface expression of RP105/CD180 and B-cell responsiveness to lipopolysaccharide. Blood 99: 1699-1705, 2002.

9. Nagai Y, Akashi S, Nagafuku M, et al: Essential role of MD-2 in LPS responsiveness and TLR4 distribution. Nat Immunol 3: 667-672, 2002.

10. Vinderola G, Mastar C and Perdigon G: Role of intestinal epithelial cells in immune effects mediated by gram-positive probiotic bacteria: involvement of toll-like receptors. Clin Diagn Lab Immunol 12: 1075-1084, 2005.

11. Clarke JH, Cha JY, Walsh MD, et al: Melanoma inhibits macrophage activation by suppressing toll-like receptor 4 signaling. $J$ Am Coll Surg 201: 418-425, 2005.

12. Munz C, Steinman RM and Fujii S: Dendritic cell maturation by innate lymphocytes: coordinated stimulation of innate and adaptive immunity. J Exp Med 18: 203-207, 2005.

13. Talreja J, Kabir MH, B Filla M, et al: Histamine induces Tolllike receptor 2 and 4 expression in endothelial cells and enhances sensitivity to Gram-positive and Gram-negative bacterial cell wall components. Immunology 113: 224-233, 2004.

14. Hasan UA, Trinchieri G and Viach J: Toll-like receptor signaling stimulates cell cycle entry and progression in fibroblasts. J Biol Chem 27: 20620-20627, 2005.

15. Peng G, Guo Z, Kiniwa Y, et al: Toll-like receptor 8-mediated reversal of $\mathrm{CD} 4+$ regulatory $\mathrm{T}$ cell function. Science 26 : 1380-1384, 2005.

16. Borsutzky S, Kretschmer K, Becker PD, et al: The mucosal adjuvant macrophage-activating lipopeptide-2 directly stimulates B lymphocytes via the TLR2 without the need of accessory cells. J Immunol 15: 6308-6313, 2005.

17. Okamura Y, Watari M, Jerud ES, et al: The extra domain A of fibronectin activators Toll-like receptor 4. J Biol Chem 276: 10229-10233, 2001.

18. Termeer C, Benedix F, Sleeman J, et al: Oligosaccharides of Hyaluronan activate dendritic cells via Toll-like receptor 4. J Exp Med 195: 99-111, 2002.

19. Johnson GB, Brunn GJ, Kodaira Y, et al: Receptor-mediated monitoring of tissue well-being via detection of soluble heparin sulfate by Toll-like receptor 4. J Immunol 168: 5233-5239, 2002.

20. Ohashi K, Burkart V, Flohe S, et al: Cutting edge: heat shock protein 60 is a putative endogenous ligand of the toll-like receptor-4 complex. J Immunol 164: 558-561, 2000.

21. Vabulas RM, Ahmad-Nejad P, Ghose S, et al: HSP70 as endogenous stimulus of toll/interleukin-1 receptor signal pathway. J Biol Chem 277: 15107-15112, 2002. 